\title{
Positional Asphyxia after Falling to Backward in a Drunken State
}

Jinhyuk $\mathrm{Choi}^{1}$, Hongil Ha ${ }^{2}$

${ }^{1}$ Department of Legal Medicine, Korea University College of Medicine, Seoul, Korea, ${ }^{2}$ Division of Forensic Investigation, National Forensic Service Seoul Institute, Seoul, Korea

Received: June 29, 2019

Revised: August 18, 2019

Accepted: August 25, 2019

\section{Correspondence to}

Hongil $\mathrm{Ha}$

Division of Forensic Investigation, National Forensic Service Seoul Institute, 139 Jiyang-ro, Yangcheon-gu, Seoul 08036, Korea

Tel: +82-2-2600-4611

Fax: +82-2-2600-4629

E-mail: sanchee@korea.kr
The deceased was found in the basement staircase of a commercial building. He was drunk the night before his death. He went into the building at 00:45 am as per the security camera recording. He was found at 9:10 am in an inverted and jackknife position causing the hyperflexion of his torso and neck. Autopsy findings revealed facial congestion and conjunctival petechiae. No evidence of critical trauma was noted. Therefore, he can be diagnosed with positional asphyxia. He must have lost his body balance and fallen on his back while climbing up the basement staircase for unknown reasons. His lower body was found to be in the jackknife position due to inertia. The drunken state and the accident prevented movement and this position was sustained for an extended period.

Key Words: Asphyxia; Accidental falls; Autopsy

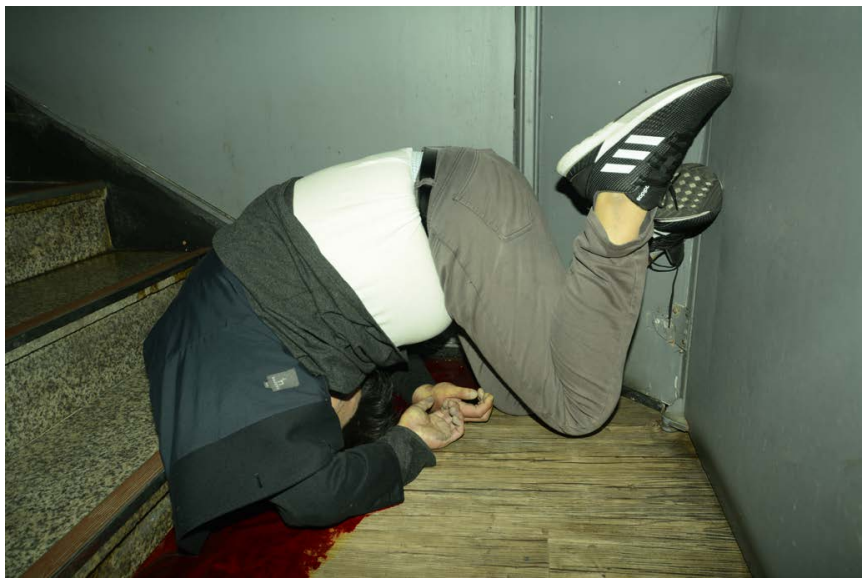

A

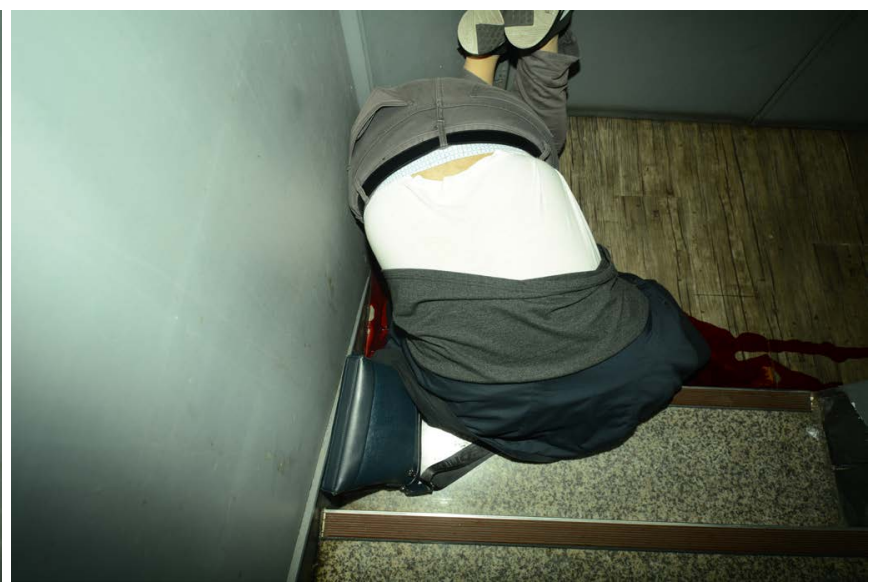

B

Fig. 1. Deceased was found in an inverted and jackknife position in the basement staircase of a commercial building. His torso and neck were hyperflexed. A pool of blood was found around the scalp laceration on the left temporal area. (A) Lateral view. (B) Posterior view. 


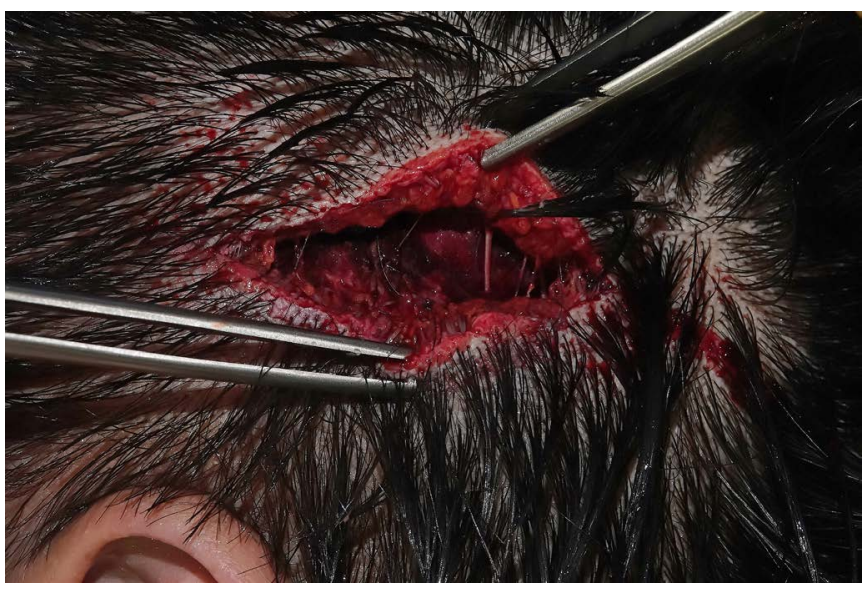

A

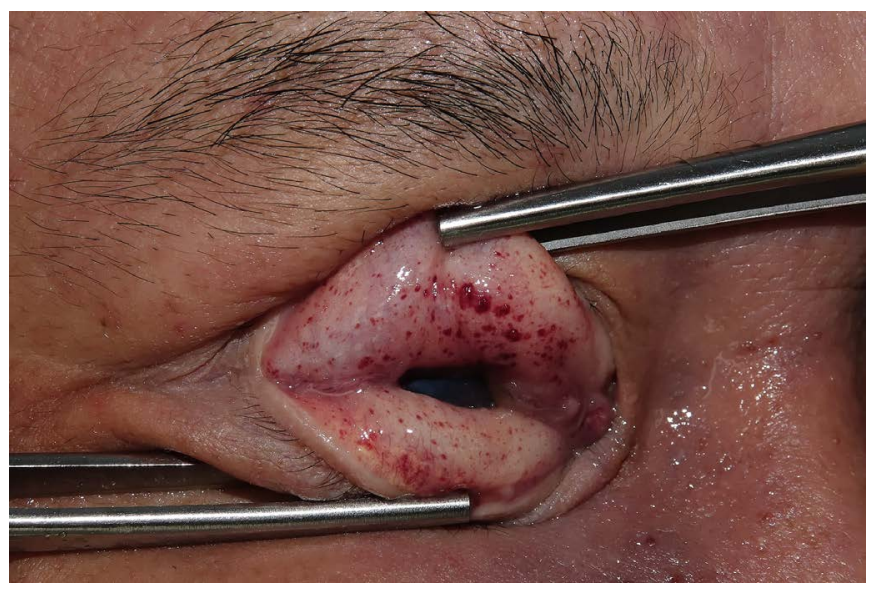

B

Fig. 2. Laceration, measuring $6.5 \mathrm{~cm}$, was found on the scalp of the left temporal area (A). Many conjunctival petechiae were observed (B).

Positional asphyxia results from a certain positioning of the body causing restriction of the respiratory movement or reduction in venous return to the heart $[1,2]$. Several circumstances such as intoxication, accident, neurological impairment, and physical restraint are considered as its predispositions [3]. Positional asphyxia can be determined after excluding other causes of death. Therefore, autopsy should be conducted for subjects found in this position under these circumstances. We report a case of positional asphyxia that resulted in death due to head trauma.

A 47-year-old man died in the basement staircase of a commercial building. He was drunk with his coworkers the night before his death. After sending his coworkers in a taxi, he went inside the building at 00:45 am as per the security camera recording. The deceased was found in an inverted and jackknife position (Fig. 1). His torso and neck were hyperflexed. A blood pool was observed around his head. The security found the deceased at 9:10 am; no suspicious person was seen up till this point on the security cameral record. The cause of death was determined as head trauma due to falling in the postmortem examination.

Autopsy was performed the next day. The height and weight of the deceased were $183 \mathrm{~cm}$ and 110 $\mathrm{kg}$, respectively. The external examination revealed a laceration, measuring $6.5 \mathrm{~cm}$, on the scalp of the left temporal area (Fig. 2A). Facial congestion and conjunctival petechiae were observed (Fig. 2B). Several small abrasions and bruises were found on both his legs. Upon internal examination, no evidence of critical trauma, such as cranial fracture, intracranial hemorrhage, and cervical spinal fracture, were noted. A small amount of vomitus was observed in the nasopharyngeal space, trachea, esophagus, and bronchus. It may have regurgitated from the stomach due to an increased abdominal pressure caused by hyperflexion. Cardiomegaly (600 g) and fatty liver were detected. The blood ethanol concentration was $0.181 \%$. Otherwise, toxicological studies were negative.

The position of the deceased made normal breathing impossible. According to the security camera recording, this position could not be changed by any other person for 8.5 hours. It was not proven that any other trauma or disease could have caused death. Facial congestion and petechiae were observed as evidence of asphyxia. Therefore, positional asphyxia could be diagnosed.

Considering the position of the deceased, the cause of death could be guessed. The blood-alcohol level of $0.181 \%$ might have caused an unstable gait due to which he must have lost his body balance and fallen on his back while climbing up the basement staircase for unknown reasons. His lower body may be positioned in a jackknife with inertia when he had fallen backward. The drunken state and the accident prevented movement and this position was sustained for an extended period [3].

Positional asphyxia rarely occurs and accounts for only $1.5 \%$ of all asphyxial deaths in Korea [4]. In literature, inverted and jackknife position is a rare cause 
of positional asphyxia. This position could be completed when the deceased fell on his back and rolled backward. In a case report, a 26-year-old man died in the same position in a trench next to a road [5]. Toxicologic analysis showed that his blood-alcohol level was $0.22 \%$. Other abnormal findings were absent. It was suspected that he lost his balance in a drunken state and fell in the trench.

If the deceased was positioned in a way that may cause positional asphyxia, thorough scene investigation and autopsy are necessary to rule out the possibility of positional asphyxia.

ORCID: Jinhyuk Choi: https://orcid.org/0000-00020316-5973; Hongil Ha: https://orcid.org/0000-00032234-5934
Conflicts of Interest

No potential conflict of interest relevant to this article was reported.

\section{References}

1. Saukko P, Knight B. Knight's forensic pathology. 4th ed. Boca Raton, FL: CRC Press; 2015. p. 366-7.

2. Benomran FA. Fatal accidental asphyxia in a jack-knife position.J Forensic Leg Med 2010;17:397-400.

3. Byard RW, Wick R, Gilbert JD. Conditions and circumstances predisposing to death from positional asphyxia in adults. J Forensic Leg Med 2008;15:415-9.

4. Park JH, Na JY, Lee BW, et al. A statistical analysis on forensic autopsies performed in Korea in 2017. Korean J Leg Med 2018;42:111-25.

5. George SB, Shetty SS, Raj MS, et al. Death due to positional asphyxia: a case report. Int J Med Toxicol Forensic Med 2016;6:164-6. 